\title{
Lymph Node Drainage
}

National Cancer Institute

\section{Source}

National Cancer Institute. Lymph Node Drainage. NCI Thesaurus. Code C18209.

The flow of fluids and lymphocytes in the lymphatic vessels, which are concentrated from tissue fluids, into a particular lymph node. Once the fluid has transited the lymph node, it is returned to the blood via the lymphatic system. 